\title{
The Unexpected Entry and Exodus of Women in Computing and $\mathrm{HCl}$ in India
}

\author{
Divy Thakkar* \\ Google Inc. \\ Mountain View, USA \\ dthakkar@google.com
}

\author{
Nithya Sambasivan* \\ Google Inc. \\ Mountain View, USA \\ nithyasamba@google.com
}

\author{
Purva Yardi \\ University of Michigan \\ Ann Arbor, USA \\ purvayardi@gmail.com
}

\author{
Pratap Sudarshan \\ Google Inc. \\ Bangalore, India \\ pratapks@google.com
}

\author{
Kentaro Toyama \\ University of Michigan \\ Ann Arbor, USA \\ toyama@umich.edu
}

\begin{abstract}
In India, women represent $45 \%$ of total computer science enrollment in universities, almost three times the rate in the United States, where it is $18 \%$. At the same time, women make up an estimated $25-30 \%$ of the HCI community in India, half the rate in the U.S. We investigate the complexities of these surprising phenomena through qualitative research of Indian computer science and human-computer interaction researchers and professionals at various life stages. We find among other things that Indian familial norms play a significant role in pressuring young women into computing as a field; that familial pressures and workplace discrimination then cause a precipitous exit of women from computing at the onset of marriage; and that HCI occupies an interstitial space between art and technology that affects women's careers. Our findings underscore the societal influence on women's representation in the tech sector and invite further participation by the HCI community in related questions.
\end{abstract}

\section{ACM Classification Keywords}

H.5.m. Information Interfaces and Presentation (e.g. HCI): Miscellaneous

\section{Author Keywords \\ Gender; India; Computer Science; STEM; HCI; IT; Education; HCI4D; ICTD}

\section{INTRODUCTION}

For about a decade now, there has been public scrutiny of gender inequality in the technology industry, and for valid reasons. Some milestones in this conversation include a 2007 UC Davis

${ }^{*} D$. Thakkar and N. Sambasivan contributed equally to this work

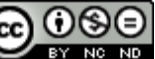

This work is licensed under a Creative Commons Attribution-NonCommercial-NoDerivs International 4.0 License.

CHI 2018, April 21-26, 2018, Montreal, QC, Canada

(C)2018 Copyright is held by the owner/author(s).

ACM ISBN 978-1-4503-5620-6/18/04.

https:://doi.org/10.1145/3173574.3173926 report noting that only $7.3 \%$ of Silicon Valley boards members were women [36]; Facebook COO Sheryl Sandberg's bright spotlight on tech-and-gender issues through public talks and a best-selling book in 2010 [56]; and Google's 2014 disclosure of the demographic make-up of its employees [6].

The aspiration is for proportional representation, but ground reality has yet to catch up. As even critics of Silicon Valley's gender inequality acknowledge, much of the gender parity challenge lies with the so-called "pipeline" that feeds into employment [26]. Women make up only $18 \%$ of computer science (CS) majors at U.S. universities, and frustratingly, this is down from a peak of about $37 \%$ in 1984 [31]. The situation is similar in other countries that are above the global average of Global Gender Gap index (referred to as genderequal countries henceforth, though inequalities persist; we mean this only relative to highly gender-unequal nations) ${ }^{1}$ e.g., UK at $18 \%$ and Sweden at $22 \%$ of workforce [17].

In contrast, human-computer interaction (HCI) is one of the few computing fields to have achieved gender parity in genderequal countries [19]. A number of factors lead to the higher representation of women in $\mathrm{HCI}$, including linking work to societal impact, creativity, and inter disciplinarity [43, 42].

In this paper, we report from qualitative research of Indian women scientists and practitioners in CS and $\mathrm{HCI}$ at various stages in their careers. How is it that in a larger social context of gender inequality, India manages to outperform more gender-equal countries with respect to computing enrollment? How long does the strong pipeline continue? And, why is the female representation poorer in HCI, when the numbers are higher in CS? Through our research, we find that socio-cultural pressures encourage, even coerce, women into entry-level programs in computing due to the lucrative and stable prospects of the IT sector. However, a drastic shift accompanies marriage and childcare expectations, with careers brought to a halt for many Indian women. In contrast to CS, HCI is viewed as an

\footnotetext{
${ }^{1}$ The global average is defined as per the The Global Gender Gap Report 2017 [1] published by World Economic Forum, measuring gender disparity across health, education, economy and politics
} 
arts field, hence considered less desirable, and compounded by discrimination issues in fieldwork and practice.

The novel contributions in this paper are as follows: First, we explore how women in the Indian computing sector experience gender-related issues across their lifetime, from undergraduates to researchers, and identify how gender discrimination and representation evolve through life stages. Against a backdrop of significant literature in gender-equal contexts, we highlight a range of culture-dependent differences. Second, we find a number of substantial differences in perceptions-by women and by Indian society as a whole - of HCI compared with computer science. To our knowledge, these have never been investigated formally anywhere in the world. Finally, we argue that it is imperative that HCI researchers participate more vigorously in understanding the human-system interface that excludes so many women. To this end, we provide some suggestions for the design, policy, and education around women's participation in computing and HCI.

\section{RELATED WORK}

Our research relates to three main strands of related work. First, the significant literature examining the many factors leading to low representation of women in computing in genderequal countries, particularly the United States where prior work covers a lot of ground. Second, a less exhaustive literature considering similar questions in India, the context of this research. Finally, feminist scholarship in HCI and computing, mainly in gender-equal countries.

\section{Gender disparity in computing in the United States}

Women in computing in the United States face stiff headwinds throughout their lifetimes. The problems begin with sociocultural factors such as gender stereotypes [32], subtle biases against girls in early education [47], and lack of encouragement and exposure [33]. These forces continue throughout formal schooling through university education leading to drop in confidence levels [12,23]. At work, related socio-cultural factors and sexism lead women to disproportionately consider leaving the workplace $[13,26]$. Issues such as gendered work environments, childcare duties, and a lack of female role models are cited as prominent factors leading to the attrition of women in science professions [62], in research [46], and in academia $[69,22]$. Current work identifies barriers at specific phases, which we extend further by comparing against various career stages in computing and $\mathrm{HCI}$ in India.

\section{Gender disparity in computing in India}

India has one of the lowest participation rates of women in the labor market at $27 \%[3,37,16]$. In India's IT industry, women were a negligible presence in the 1980s, but their numbers have steadily grown since, comprising approximately $30 \%$ of IT workers today [65]. In other words, women in Indian IT have matched the rate of participation of women in the general workforce. The change has been attributed to market forces and changing social norms related to the booming IT economy within the constraints of a patrifocal society [27]. However, women's participation is disproportionately limited to junior positions ( $80 \%$ by one measure [53]), and the same "glass ceilings" afflicting U.S. tech companies appears to exist in
India as well [28]. Venkatesh et al. [66] find that in STEM research careers, promotions depended more on gender than on productivity. Gupta [29] notes that social prejudice against working women greatly limits women from obtaining top positions. Although the above work addresses Indian women's technology careers in piecemeal fashion, no systemic analysis of their career trajectories has been conducted. Our study performs such an analysis across women's various adult career life stages. To the best of our knowledge, prior research about women in $\mathrm{HCI}$ in India does not exist.

\section{Feminist $\mathrm{HCl}$ scholarship}

Gender studies has a long history of investigating women and work (e.g., [15]), and the gender lens has been extended to the field of HCI $[38,5]$. Issues central to feminism such as agency, identity, subjectivity, and cultural difference have been brought to light in HCI, by Bardzell and Churchill [5, 4]. Satchell [57] and Inkpen [35] have argued for considering gender in design practices in HCI. Kotamraju [38] and Light [40] have discussed the gendered identities of female researchers and the performative acts they play in conducting HCI research. To further the community of female HCI researchers and feminism in HCI, several workshops have been held $[19,18]$. While gender-sensitive design practices and values have been a major area of inquiry in HCI, less attention has been paid to the representation and experiences of female HCI researchers globally. One exception is work by Dray et al [19], which found that women in the Global North are attracted to HCI owing to its creative bent. In this work, we seek to broaden feminist HCI scholarship to the Indian context with an intersectional lens [58]. We apply a pluralist [5] approach and contribute to the body of knowledge about factors affecting CS careers in the Global South.

\section{BACKGROUND}

We provide a brief history on CS \& IT education in India along with the evolution of $\mathrm{HCI}$ over the years.

\section{History of IT and CS education in India}

The first formal computer science program in India was introduced in 1980 [55]. Currently there are over 10,000 institutes in India that offer engineering degrees; nearly as many institutions offer CS \& IT degrees. Several computing bodies and prestigious conferences have a presence in India, including an official ACM office and a Grace Hopper Conference-India. Students are generally pushed into medicine and engineering, including IT and CS by parents [55]. The undergraduate program is generally rigid - curricula are fixed with little flexibility to try out different courses, and switching majors means re-starting the program from year one.

\section{Growth of the Indian IT industry}

The Indian IT and IT-enabled services industry is a highgrowth sector, contributing 9.5\% of the GDP in 2016, employing 3.9 million people directly and generating USD 120 billion annually in revenue [34]. The history of IT growth in India can roughly be divided into three phases. In the first phase, India emerged as a destination for outsourcing and 'offshore' business processing office (BPO) jobs. Growth of the IT 
industry began after 1991 when India defaulted on its debts to the IMF, hence liberalizing its laws for the IT industry as a new growth engine. Concessions were created to open new software 'technology parks' with satellite technology to manage off-shore client requirements. The industry further saw a spurt in growth in 2004 when the new government declared "IT as India's tomorrow," creating infrastructural reforms in banks and public sector to install software infrastructures [55]. Entire suburban technology townships emerged, such as Hyderabad's HITEC city, Bangalore's Electronic City, and Chennai's IT corridor. In its second phase in late 2000s, Indian engineering talent and vast consumer base attracted software development offices of multinational corporations like Cisco, Google, and Microsoft (India was often the site of these firms' first engineering centers outside the Global North). In its third phase as a more mature technology industry in 2012, India attracted over 4 billion USD in venture capital funding [2] with over 4,500 homegrown start-ups [54]. More than 50\% of the incubators were set up between 2012-17 [54]. Many of these startups have been successful in gaining user adoption among Indians, such as Flipkart, Myntra and Saavn.

\section{$\mathrm{HCl}$ in India}

HCI growth in India has not kept pace with the growth of the software industry. HCI is offerred as an elective at some universities; an HCI track was offered as part of a Bachelor in Design degree at the Indian Institute of Technology (IIT) Guwahati in 2003; but HCI is not offered as a full program at the undergraduate level in any Indian university. Only two central universities offer a PhD in Interaction Design currently (IIT Guwahati and IIT Bombay).

But, the field is growing. The first HCI conference was organized in 2004 by the HCI Professional Association of India, with close to 30 attendees. It is now held annually and invites conferences like Interact to India. The Indian HCI community has an informal mailing list with around 2,700 members since circa 2001 but the forum is active mainly for administrative purposes only. Practitioners in our study estimated the size of the HCI community to be around 10,000 people (compare this with 600,000 students graduating in CS every year).

With India transitioning from outsourcing work to product development for its own consumers, $\mathrm{HCI}$ is increasingly integrated into Indian product development cycles. HCI and UX jobs are growing in industry, for user researchers, visual/interaction designers and prototypers.

\section{METHODOLOGY}

We gathered data on Indian women and computing through 39 semi-structured interviews and 3 focus groups. We conducted a total of 50 hours of interviews and 8 hours of observations. Table 1 summarizes participant demographics.

The study was designed to include Indian women in all stages in the tech sector, spanning industry IT practice as well as academic research. The sampling aimed for a mix of geographical origin and site of university education (India and USA). The interviews were conducted with female undergraduate (UG) and graduate $(\mathrm{PG} / \mathrm{PhD})$ students in computer science, $\mathrm{HCI}$ students (HCI), IT employees (IT), and both junior (JR) and senior (SR) professors, industry research scientists (IR) in computer science and UX researchers (UX) in industry. We additionally interviewed HCI professionals in India who pioneered HCI in India, both in academia as well as in industry.

University students (undergraduate, master's, and $\mathrm{PhD}$.) were those who attended top-tier national and regional universities in India, some of whom also had experience with graduate school in the United States. The students were recruited through university faculty, Android developer groups, Women Techmakers events, and snowballing. Research scientists and IT professionals were identified through university and corporate websites and contacted by e-mail. Faculty in our study were recruited from premier computer science research universities in India through e-mail.

Almost all of the interviews were conducted in person, with the exception of two interviews conducted via video calls. Interviews were audio-recorded and transcribed. Interviews were conducted in English, the language of choice of our participants. Though we did not constrain recruiting by sexual identity or orientation, all of our participants identified as heterosexual cis-gender women.

Observations of computer science events and initiatives were conducted during June 2016-August 2017. These were conducted at Lean In Bangalore, Technovation in the San Francisco Bay Area, and Google Science Fair in New Delhi.

\section{Study Questions}

The interviews were designed to capture major motivating factors, challenges and experiences with respect to computing education and careers at various life stages. The questions were focused on childhood years, formal education up to university, university education, and professional life, with an emphasis on eliciting concrete personal stories. The interview protocol included questions about participants' women peers and gender biases, personal and professional experiences, and sex-based discrimination faced in their place of work. Participants in HCI professions were additionally asked about the challenges of HCI research in India.

\section{Data Analysis}

We carried out a structured, qualitative data analysis to summarize and interpret the interview data we collected. Our analysis approach drew from related literature and existing theoretical understanding of the subject. Interview data were analyzed using a general inductive approach [63]. Interview transcripts were read multiple times, affinity clusters were developed, and key themes were derived and iteratively refined. The emergent themes were aligned with life stages, which provides the organizational structure in our findings.

\section{FINDINGS}

We analyze factors affecting Indian women in their journeys through computing education (undergraduate, master's and $\mathrm{PhD}$ ) and careers (both IT and research or academia). Throughout the findings, we compare findings from India with related literature on the Global North, particularly the United States, where robust data are available across life stages of women in 


\begin{tabular}{lll} 
Phase & No. & Locations \\
\hline Undergrad (UG) & 5 & Bangalore \\
Master's (PG) & 4 & Bangalore \\
HCI students (HCI) & 7 & Ann Arbor \\
PhD (PhD) & 11 & Chennai, Bangalore \\
Asst profs (JR) & 5 & Mumbai, Bangalore, Chennai \\
Assoc \& Full profs (SR) & 4 & Mumbai, Bangalore \\
IT employees (IT) & 5 & Bangalore \\
Industry researchers (IR) & 2 & Bangalore \\
UX researchers (UX) & 5 & Bangalore
\end{tabular}

Table 1. Demographics of the research study participants.

CS. Figure 1 explains the various motivators and inhibitors for women in CS at every life stage. ${ }^{2}$

A broad overview of our findings is as follows: Initially, through undergraduate and master's programs, socio-cultural pressures encourage women to enter CS as a field, with parents in particular expecting better financial and marital prospects. However, as women advance through further education and early careers, their ambitions meet familial duties and societal expectations. Marriage and childcare norms in India saddle women with a burden even heavier than that felt by their peers in gender-equal countries. Thus, participation of women starts unusually high but then experiences a dramatic drop: from $45 \%$ among undergraduates, to $30 \%$ in the IT workforce, to around $10 \%$ of CS researchers, and less than $1 \%$ of C-level executives in the IT sector. The situation for women in HCI differs in particulars, but the overall patterns are similar.

\section{Childhood: little gender bias}

We start with a brief overview of childhood factors influencing computing participation, based on recall experiences. CS is introduced as a course in sixth grade as per the National Council of Education and Training (NCERT) curriculum [50] which is followed in all schools affiliated with the Central Board of Secondary education. The lack of biases at early stages and early introduction of CS leads to a level playing field. One of the surprising findings of our interviews was how few participants mentioned any concerns about their ability to do technical work either in an absolute sense or relative to men, in sharp contrast to the U.S. context [14, 49, 60].

\section{Undergrad: bright futures through $\mathrm{CS}$}

India's booming IT industry makes it a prime employment destination for middle class India. Its IT industry has been consistently growing since economic liberalization in 1991 [55], creating as many as 3.7 million jobs per year [61]. Multinational technology companies pay engineers well. [9]. Families are keenly aware of these economic prospects, which also affect marriage options-a process that is highly formalized.

\footnotetext{
${ }^{2}$ Sources for India stats: All India Survey on Higher Education (AISHE) report (2015), Women and IT scorecard by NASSCOM (2017), ACM India computing survey (2017), HCI estimate by full professor (2017). Sources for U.S.A. stats: National Science Foundation (NSF) Women, Minorities, and Persons with Disabilities in Science and Engineering Report 2017, User Testing UX and User Research Industry Survey (2017), J. Kaye, Some Statistical Analyses of CHI (2016).
}

CS is in strong demand at the undergraduate level. Consistent with other studies [48], one finding is that parents have significant say in their children's career decisions. Families look to their children to uphold and promote their social and economic status [65]. Lower and middle-class families generally expect their children to provide them with security in old age. A participant notes the difference in opinion with her parents:

I'd have wanted to do a BSc in Math but my parents led me to a CS degree. I soon realized the economic benefits of CS and gradually grew fond of it. - SR3

CS programs in premier institutes like the Indian Institutes of Technology (IIT) are extremely competitive, admitting only the top $0.2 \%$ (out of 1.2 million who appear for the required entrance exam), [52]. Providing nuance to findings of gender parity [20], our participants reported not feeling "smart enough" as compared to their male peers at premier institutes. However, we did not observe any gendered self-confidence issues moving to master's and $\mathrm{PhD}$ in elite universities.

Participants reported that they were attracted to the economic stability of CS and its high paying jobs. They pointed out that self-sufficiency and financial independence (even from their husbands and parents) was important to avoid the burden of any form of harassment in the future. IT-related jobs are considered "safe" for women because they are white-collar jobs in which employees interact with a narrow, educated stratum of society. Physical safety was noted as a deep concern for women in India, and particularly for their parents, who tend to imagine sexual assault as an ever-present threat. Parents thus see in CS jobs innocuous desk jobs, air-conditioned offices, and secured buildings with gated entrances. Even compared with other engineering disciplines, CS is a safe bet; mechanical engineers, in contrast, may be required to do physical tasks on a shop floor or to interact with people doing menial work. Our participants reported that their parents discouraged or forbade any career involving physical hardships, late nights, or the perceived possibility of physical assault.

Finally, in a few cases, women expressed that their gender worked to their advantage in the university. IR3 noted that women received gentler treatment in lab courses and higher grades in some classes. The value of this kind of special treatment is dubious, however. In a few instances, our participants related missed opportunities where male students were favored for challenging projects by male faculty.

\section{Master's degrees: recovering agency}

Master's degrees in CS are seen to have the same advantages as CS undergraduate degrees, but with greater force: even better job and marriage prospects. Our participants reported that a master's degree was a matter of honor for the family and a boost to the marital profile of the participant. (Arranged marriages in India are often preceded by an offline or online exchange of "profiles"-marriage-related resumes.) Several participants noted that their degrees were prominently printed on wedding invitations, and, in some cases, the degree signaled the proportionate amount of dowry paid by the daughter's family to the groom. 


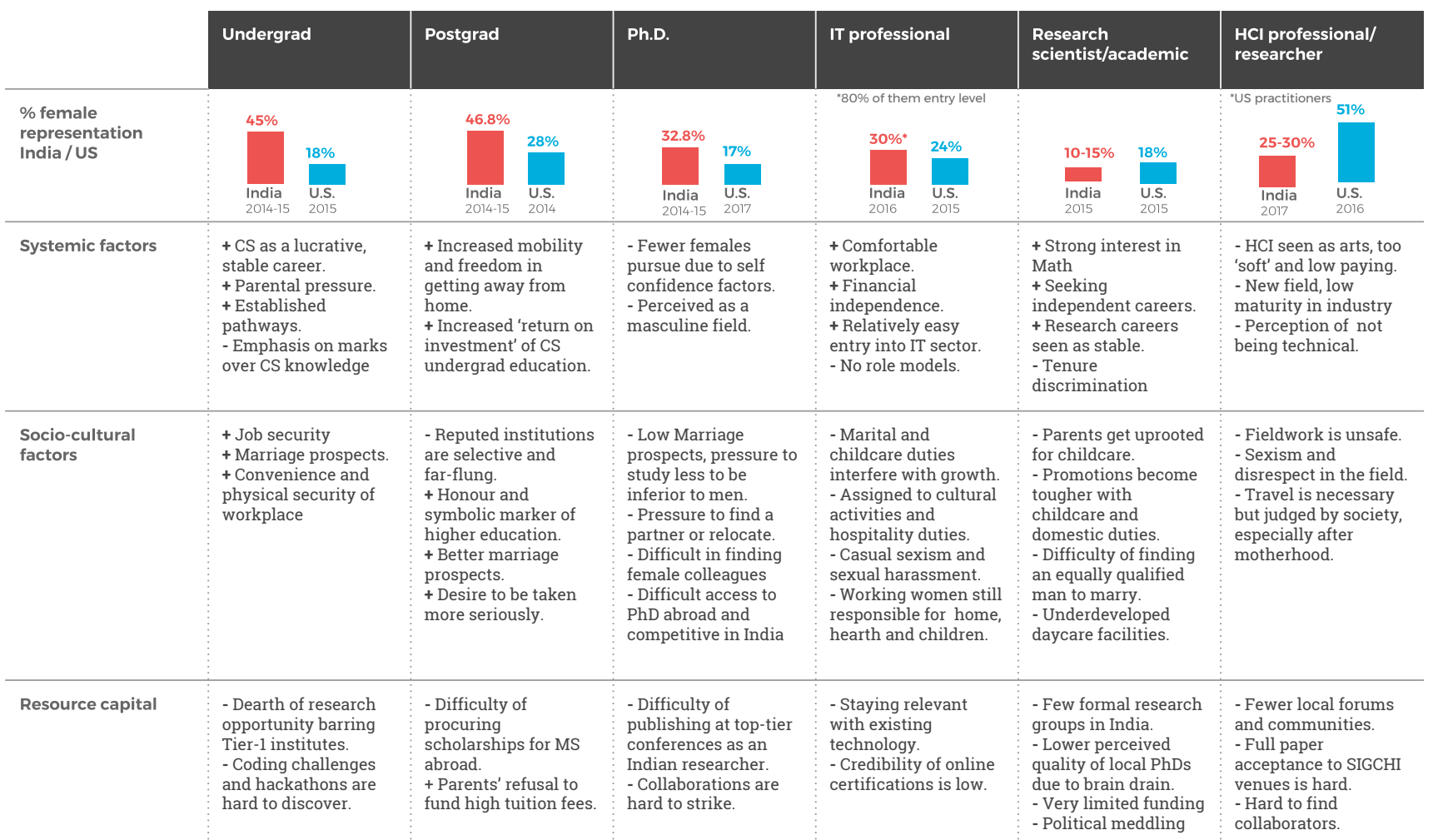

Figure 1. Factors affecting the CS/HCI pipeline in our study

A master's degree provided the ability to find more meaningful work through specialization, or in the case of HCI, to pursue creative passions within the IT industry. Five Professors in the study said, the master's degree offered women more freedom in a socially acceptable way to postpone marriage or work. Two participants cited narratives of rebellion and subversion when being pressured to marry at this stage, through tactics such as pointing to an elder sibling who was not yet married (social norms expect children to be married in their birth order). One participant said,

My elder sister got married soon after [the 10th grade]. My younger sister, while I was an undergraduate. That pressure didn't come to me because I was very good at studies [and went on to a master's degree]. - SR3

Funding was crucial at this stage. Since family funds were allocated for larger expenses like weddings, justifying the tuition was noted to be challenging. Scholarships were reported to have enabled ten of the sixteen participants from academia, industry and UX to pursue master's degrees, when other financial means were limited.

\section{Related work from gender-equal countries}

Notably, we found little evidence during schooling of Indian women facing the challenges faced by their peers in genderequal countries. Studies in gender-equal contexts identify gender stereotypes fueled in part by the subtle biases by teachers in early education [47]. Stereotypes give rise to a maledominated geek culture that is likely to emerge amongst boys where they may crowd out those (likely women) who feel anything less than ardor for the subject [44] and might eventually lead to loss of interest and aspiration for women to pursue CS [49]. These issues were rarely voiced by our Indian participants.

\section{PhD: marriage pressures and isolation}

Only $32 \%$ of the $\mathrm{PhD}$ cohort in CS-related fields in India are women [51] as against $47 \%$ at the master's level. A common theme among our participants was that while there was encouragement to pursue undergraduate and master's degrees in CS, it did not extend to $\mathrm{PhD}$ These concerns were largely related to issues around marriage and adult dynamics in India.

\section{Who will marry you?}

Families actively discouraged their daughters from pursuing PhD's out of fear that they would became "too educated to be married off." Sociologists have identified a tendency for women to "marry up" [24], and in India, this inclination is formalized in arranged marriages, in which it is assumed by all parties that the bride will be of lesser status than the groom. The same norms, of course, expand opportunities for men with more education. And, these norms are often internalized by women themselves. One of our participants noted,

My concern was if I become over-educated, I won't find a man. I wanted to get married and have kids...As an over-educated woman, you expect to find a man at least as good as you so your options become limited. - IRI

In addition to the fear of over-education, there was an agerelated pressure to marry at the "right time." Parents were 
reported to feel an obligation to ensure their daughters' marriage and it was expressed as an overt or covert pressure for their daughters to marry soon after obtaining bachelor's degrees. Considerable stigma is attached to single women past their mid-20s, with parental concerns ranging from social perception, diminished potential for marriage, or threats to future childbearing. One of the participants reported that balancing the need to appease parents with the pursuit of academic responsibilities led to mental stress, anxiety, and depression.

Indian parents often save for daughters' weddings in the same way that American parents save for college tuition [7]. Our participants thus reported that they could not have entered doctoral programs without guaranteed funding, since their parents refused to pay for $\mathrm{PhD}$ education, and taking on loans was prohibited (another liability for marriage).

In case of married participants, their life decisions were often determined by the husband and his family. This appropriation of agency led to complex negotiations across desires, value systems and priorities. There were instances reported around struggles to convince their in-laws about temporary relocation to finish their doctoral programs. Participants spoke about colleagues from their university who did not continue with a research career because of lack of support from in-laws. An associate professor in our study noted:

A brilliant classmate of mine was from a small village... Her parents forced her to get married on the condition that she'd only complete a MSc. The friend really wanted to do a PhD. She was hoping her husband would allow her to do an MPhil, but he didn't. - SRI

Marital concerns intersect with geographic mobility to cause problems for womens hoping to pursue PhDs. Doctoral studies are often constrained by advisor location, hence pursuing a $\mathrm{PhD}$ often requires moving away from one's home town. Three out of nine faculty who had moved away from home reported that such moves offered new-found freedom away from close family scrutiny, but others reported challenges for marriage. As in other cultures, social pressures for wives to move where their husbands work is more intense than the converse.

\section{Community, collaborations and role models}

The lack of aspirational role models (for upward mobility) outside family was a concern not only for oneself, but to show as an example to their family as well. Participants found it hard to collaborate with their male colleagues due to restrictions placed on them by their parents and educational institutions or for the fear of appearing too forward. Some reported participating in online groups by assuming gender neutral identities to avoid unwanted attention. These constraints faced by the participants lead to an isolating experience.

A distinct lack of aspirational role models was reported. Participants noted that while there was an abundance of familial and relational role models (siblings, cousins, mothers), aspirational figures to emulate for further education and career success in computing were limited. The absence was especially profound for participants hailing from rural and peri-urban areas. Female role models were difficult to find, especially in families where the participant was the first person to break socio-cultural cycles. Relatable role models served an important role for the entire family as much as they did for the scholar or student. Our participants noted that the presence of a role model from a similar community/region as theirs would help them start a dialogue with their parents/partners about their independence and careers. PhD5 discusses the importance of relatable role models:

When I search online for CS leaders and lectures, all I get is male professors. There are no women, forget Indian women. I can't show my mom a Sheryl Sandberg and say I want to be like her. - PhD5

Our participants could not take advantage of in-person study circles, an important aspect of peer learning, due to reservations in interacting with male colleagues. Gendered hostel curfews (women typically have a curfew; men do not) made it difficult for men and women to collaborate. Calling male colleagues over the phone for any help was viewed as "desperate," limiting conversations to social media channels. Requests of help were sometimes misconstrued by male classmates as sexual or romantic advances. (In IT11's case, men explicitly expressed a need for sexual and romantic favors in return for collaboration.) In a couple of instances, men were reported to be unwilling to include women in discussion groups even at the $\mathrm{PhD}$ level because of their discomfort.

Technology was instrumental in managing the gendered identity, by allowing participation, finding collaborations, and sustaining careers. Communities like Github, Stackoverflow and GeeksforGeeks were used anonymously or with e-mail logins to engage with the wider competitive programming circles. Social media handles were avoided publicly in order to fend off subsequent unwanted male advances in the form of incoming friend requests and messages (including nude pictures).

\section{Related work in gender-equal countries}

In the literature from gender-equal countries, lack of role models, encouragement from faculty [30] and academic institutional practices [21] are cited as barriers to women to pursue doctoral studies in STEM fields but the single largest bottleneck is the representation of women in early education [8]. This bottleneck does not appear to exist in India leading one to conclude that the pressures to get married and isolation from the lack of community are the primary factor in the discouragement of women from doctoral studies.

\section{Careers and practice: sharp drops due to family life}

India women represent a greater share of CS employment than in the overall labor force (30\% of IT employees are women compared to $25 \%$ overall). In contrast in the United States, the percentage of women in CS is less than half of overall women's participation in the workforce ( $24 \%$ in IT vs. $46 \%$ overall) $[3,53]$. Even though the percentage of women in leadership positions in both countries is minimal, in India, it is only $1 \%$ women in executive positions (cf. $5.2 \%$ in U.S.A.) [53, 39]. Much of this is explained by the stark drop by women in the Indian CS workforce as they approach the age of 30. Marital and familial responsibilities interfere with career progress. 


\section{Marriage and childcare}

The women in our study noted that their career choices involved multiple stakeholders (husband, parents, and in-laws). Practices and policies around maternity leave further led to discrimination.

In India's patriarchal society, the onus of domestic labor falls unequally on women. Indian men notoriously do the least amount of housework compared to most other countries (Indian women spend 298 minutes daily on domestic chores while men spend 19 minutes; in America, the figures are 126 minutes (women) and 82 minutes (men)) [10]. Even senior researchers in our study managed a full day of work in the office and went home to domestic duties. Nine of the eleven researchers (academic and industry) we spoke to reportedly employed domestic help (household labor is relatively affordable in India), but their management was still reported to be a time-consuming task by our participants. Childcare was squarely a gendered job. Consequently, there was little time for self-care and extra-curricular professional work. Despite juggling professional and familial duties, six out of eight professors with children expressed that credit was unfairly not attributed to them. IR1 discussed how her partner was elevated socially when performing the same duties as her, and how the very act would lead to society's judgment of her failing in her motherly duties.

India has a 26-week maternity leave policy (paternity leave is only mandated for public sector jobs, for a short 15 days). However, workplace re-entry and re-integration policies were reported to be weak. Participants discussed how daycare centers were not well-developed in India, with no formal training for center operators. Taken together, the impact of the long absence from the workforce had drastic, discriminatory consequences for our participants. Participants from academia reported that the lack of fluid time owing to domestic and childcare responsibilities affected their work patterns. Participants from the industry noted that having a baby after having established themselves as indispensable to the company had a significant impact on the flexibility they received from the company. IT12, an ex-engineer described that she was moved from a software development role to testing against her will, upon returning from her first maternity leave. Quitting after her second maternity leave, she was unable to find entry back into the software industry after two years, at the time of the interview.

\section{Software careers}

Structurally and culturally, the Indian IT industry presents disproportionate challenges for women. The emphasis on late night shifts was challenging for women with families; physical safety issues present obstacles to mobility and social acceptance. These factors attribute to the drop in the representation of women from $80 \%$ at entry level to $25 \%$ at managerial positions to less than $1 \%$ in the $\mathrm{C}$-suite [53].

Despite India's IT industry boom, the structural design of the technology sector is antagonistic to women's success. Success in this work environment and team culture depends on physical presence in meetings, brainstorms and check-ins. Though progressive companies provide the option to work from home, getting work done in a remote environment was viewed as "chilling out" and few steps were taken towards inclusion in remotely-distributed meetings. IT12 described how working from home could only be used for 'legitimate' emergency situations approved by her manager, such as children's sickness. Participants expressed that promotions were denied despite having scored well on performance cycles, with the reason for denial being "not being around." The average Indian employee spends 52 hours per week at work, which is higher than most countries [59] - a situation which does not translate well to competing childcare and household obligations.

Safety and security were other issues that affected our participants. IT outsourcing work hours often involve late-night shifts with socializing after hours. Many of India's IT hubs have emerged in recently urbanized suburban locations, due to tax cuts and large real estate spaces. Locations like Gurugram drastically reduced women's physical mobility at night, requiring security escorts even in company cabs. Working long hours or night shifts placed severe restraints on women's ability to access their workplace, vis-a-vis their male counterparts. IT14 notes:

I am scared to go from my office to home in the night fearing instances such as rape and sexual harassment specifically in my city. I have to ensure that I go back with a male colleague in the night. The lack of public transport at night worsens things.- IT14

\section{Research careers}

Nine out of ten female professors in our study were married to fellow researchers; while these relationships were cemented on compatibility, mutual attraction and other factors, preemptive avoidance of being married (through arranged marriage) to a male member from another profession was cited as a factor. In this India-specific two-body problem, women felt sidelined compared to their partners. They further encountered discrimination in promotion decisions.

Participants expressed an interest in flexible work hours, drawing a distinction from "not lower standards or less work pressure, but just flexible time" to be evaluated on equal terms as male counterparts. JR1 articulated that "the responsibility needs to be shared between men and women, and women should not have to lift the family's burden with no help from the man." If a couple was working together, it was assumed that the husband was the intellectual contributor or that academic collaborations were initiated with the husband even if both partners were involved.

Either through first-hand experience or second-hand knowledge, five research participants reported that tenure cases were delayed compared to male colleagues. The delays were reported to add to stress, as participants proactively wanted to prove their capabilities early on in order to get promotions they deserved at a normal cycle. JR3, an assistant professor at a top-tier public university, noted that for a maternity leave of six months, her tenure case was delayed by two years.

\section{Related work in gender-equal countries}

Marital responsibilities and child-birth are well documented as impediments to a woman's academic [46, 69] and professional 
careers [45], they're exacerbated in the Indian context because of the above mentioned factors. The discriminatory practices and policies in the professional [45] and academic environment $[22,68]$ seem a commonality across U.S and India.

To summarize, socio-cultural pressures encourage women to enter CS for education. However further along the CS journey, marriage pressures, houseword and childcare duties, and discrimination hinder women's professional growth. We next address issues specific to HCI, as they differ from CS.

\section{$\mathrm{HCl}$ in India: artsy and second choice}

Traditionally, computing serves as the broad umbrella under which HCI sits in collaboration with design, information sciences, human factors or cognitive sciences. The interdisciplinary nature of $\mathrm{HCI}$ results in multiple entry points into the field from various disciplinary backgrounds. We turn our spotlight on how HCI experiences for women differ from CS. All of the above factors on discrimination and societal pressures in doctoral education, research careers and software jobs still apply to HCI careers.

\section{$\mathrm{HCl}$ perceived as arts}

In contrast to how HCI programs are placed under the aegis of computer science or information schools in the West, $\mathrm{HCI}$ in India is placed within design departments. This translates to HCI being viewed as 'fine arts.' Students earn a bachelor's in design or art, as opposed to engineering or science. The image of HCI as 'arts' in the Indian context implies that it sits low on the economic hierarchy of desirable subjects. It is widely believed that students who cannot get into the high-paying and 'challenging' fields such as engineering and medicine pursue the arts. Because of this association, the social factors that encourage women into computing work against HCI programs. Consequently, an estimated 25-30\% of HCI master's and PhD students from leading institutes are women. So why are more men in HCI when it is considered to be the arts? Indian HCI pioneers in our study pointed to how the field was created and instituted by designers, who were predominantly men-this gender imbalance continues to propagate today. As a new field that has not yet achieved legitimacy in India (that HCI can lead to prestigious jobs in the tech sector or in academia is not yet well-known), women hesitate to enter HCI.

Entry into a master's program in HCI requires a candidate to take a design 'entrance exam', unlike in the United States where diverse undergraduate degrees can be sufficient for acceptance. Most universities in India do not support multidisciplinary programs or minors. Therefore, it was reported that when students from various backgrounds entered HCI programs, transitioning to an inter-disciplinary space was challenging. Faculty members reported spending a substantial amount of time on design basics rather than research methods in order to prepare students for industry in a short time. The lack of focus on research is further affected by the relatively short program completion time of two years, where students need to master design fundamentals, learn tools of the trade, write a thesis, and develop a portfolio.

Industry funding and demand for UX designers and usability professionals result in curricula focused on applied research and getting students industry-ready. The emphasis on applied research diminishes alternative inquiry and epistemologies in HCI, such as critical theory and social science methods, creating unfamiliar environments for students who decide to pursue research in HCI during a PhD. The lack of awareness about research expectations is exacerbated by the small research community, making it difficult to discuss research ideas, share resources, and find collaborators. Consequently, there is relatively lower research output, which in turn affects representation in top-tier HCI venues.

\section{Gender discrimination in fieldwork}

Fieldwork is a critical aspect of HCI research, and this is particularly true in India, where a disproportionately high amount of HCI work occurs with low-income communities. Participants were viewed as sexualized beings rather than HCI professionals by a whole range of entities from research participants to accommodation providers.

Travel after marriage and motherhood was reported to be challenging, as women were viewed negatively for appearing to abandon their domestic duties. Participants reported facing rampant sexism and disrespect in the field. Gaining entry in rural communities meant creatively disregarding or overcoming challenges and threats from male members. Entering normalized power structures in male-dominated spaces, in contexts where women are often considered inferior, implied that those associations carried over to the female researchers, too. As JR4, a social scientist, notes:

I face a lot of harassment during field work in rural India... While interviewing men, they would smoke beedis (cheap cigarettes) in my face. - JR4

Female HCI researchers reported facing issues with room bookings in hotels (where single women seeking rooms are suspected to be sex workers) and solo travel in buses and trains (sexual harassment) - activities that are necessary for any field research. In turn, these societal responses restricted the researcher's mobility and freedom. UX1, recalled her experience conducting fieldwork in small towns:

When I used to stay alone in hotels, people would give me dirty looks. To avoid any bad incidents, I used to go to my room at $7 \mathrm{pm}$ and leave at $8 \mathrm{am}$, not even come out for dinner to not face those weird stares. - UXI

Single women conducting research were often viewed as 'available' and 'loose,' with phone numbers and names exchanged during recruitment later used for sending friend requests and messages. 3 UX Researchers reported sharing fake or incomplete identity details, maintaining two SIM cards, and using outward markers of married identities. Sometimes, this meant having uncomfortable conversations with forward participants. ("I had to tell this one study participant who said he liked me and wanted to be romantically involved that I was married.") Families of female researchers that travel alone were justifiably worried, but in a few cases, to the point of requesting a call every hour to report safety status. 


\section{Feminist connotations}

The Indian HCI community has created a few support groups and fora for women in HCI. Even these fora were not free from unwanted advances. Despite an explicitly worded meeting invite for women in UX, a meetup by one group was attended by $60-70 \%$ men. UX3, the organizer of the event described the modifications made as a result:

These men were coming to meet other girls at the event. So now we have started a "Happy Hour" where every man has to bring a woman in $U X$. - UX3

The branding of women in HCI events impacted attendance and involvement. In one of the sessions, a feminist HCI talk was arranged. However, the session saw poor attendance by both men and women. As the organizer noted, "the term 'feminism' is almost abused in India, so much that it has lost its real meaning." Feminism is deeply misunderstood by both men and women in India, often perceived as male-bashing in many circles. Just for example, a popular Bollywood actress Parineeti Chopra commented, "I want girls to be treated the way men are... So, I do want to be a role model, but not a feminist" [64]. The languages and comprehensions around gender equality in various global contexts further call for reflection on the critical discourse on feminist HCI worldwide.

\section{Gender in everyday $\mathrm{HCl}$ practice}

Everyday discriminatory acts were noted to occur in the workplace, similar to the previous section, but in core HCI activities of design critique, brainstorming, and collaboration. A few participants reported facing unfair criticism when presenting research insights or designs. Brainstorming, ideation and collaborative analyses are critical to HCI research and practice, and depend upon impartial representation of voices. Yet most HCI participants reported being undermined by being talked over and having to play dumb in collaboration sessions.

\section{Related work in gender-equal countries}

Unlike in India, related work in the United States suggests considerable gender parity in HCI [19, 18, 44].

\section{DISCUSSION}

Our findings suggest a number of ways in which technology companies, Indian policy-makers, and academic institutions could support women in computing and HCI careers. We divide our discussion into those that we believe are broadly societal and hence more challenging to change, and those which we believe the $\mathrm{CHI}$ community can address.

\section{Better workplace policies}

Solutions used in gender-equal countries to address the "leaky pipeline" in the workplace should be considered in Indian technology firms and universities, as the problems seem to be similar and at least as problematic. Everything from gender-equal parental leave policies, to diversity workshops, to systematic recruiting outreach to women is likely to have some impact. Re-integration back into work and fair, consensual assignment of work roles after long leaves are crucial to equitable treatment (see [67] for potential solutions). Work from home is problematic without corresponding policies on inclusively integrating remote employees. Everyday biases could be significantly reduced by regularly sensitizing employees about their unconscious biases, especially those resulting out of ignorance and blind adherence to social norms [41]. Technology firms should be called to take up global gender-equity causes publicly. Fair and inclusive environments further enable equal female participation in various aspects of HCI research and practice, such as fieldwork, brainstorming, design critique, or usability studies. Ultimately, gender parity of HCI researchers enables better design for end-users as a whole $[4,5,19]$.

\section{Familial support systems}

Our research points out that it is insufficient to have early CS education or a passion for computing; without the support of family members and society, women will continue to face the burden of navigating social norms in making progress in their careers. To erode societal stigma against PhDs for women, parents of junior practitioners and researchers may be targeted in re-shaping deeply ingrained societal attitudes on women's gender roles (see, for example, [66]). Partners in later stages should be included in efforts to encourage women's career successes, since they are crucial in financial and emotional support, and earning the backing of in-laws. This may take the shape of easily accessible programs for parents or partners to code, enabling 'take your parents or spouse to work' day more widely, and open house fora (such as the Indian Institute of Science's Open Day initiative for parents). These initiatives expose family members firsthand to the benefits of being in senior management, instill empathy, and make computing more human-friendly. It may be helpful to run social marketing campaigns that highlight women with $\mathrm{PhDs}$ who also have "successful" families. Of course, any such messaging must take pluralistic viewpoints into account, such as not further stigmatizing unmarried women or those with non-heteronormative identities and not marginalizing those who may not live with or have immediate family members. There may be technology solutions at the margins, mediating between parents and their daughters. For two decades now, many arranged marriages in India begin online with matching sites such as Shaadi.com. Such sites could offer options for women's families to identify men who support prospective partners' further education or prefer highly qualified women.

\section{More relatable role models}

Relatable role models serve an important role for the entire family as much as they do for the scholar or student (in contrast to lack of role models for only the individual in the United States [62]). However, as noted earlier, local, aspirational role models are difficult to locate within social circles. (Role models are nearly impossible if the female scholar is from a village and is the first person to break the patriarchal norms around education.) Technology and mass media platforms have an important role to play here in serving aspirational local figures and their stories, across a spectrum of gender roles, class, language, and sexuality, and improving discoverability of this content (see, for example, [66, 69, 22].

\section{Financial support for advanced education}

Given that family support for women to pursue CS degrees starts high at the undergraduate level, scholarships and sub- 
sidies for women seem best targeted to master's degrees and $\mathrm{PhDs}$. Such support would enhance women's agency to pursue advanced higher education, to make up for waning familial resources and moral support. As seen above, not only do financial incentives serve a practical purpose of avoiding student debt or placing less financial burden on parents; they further serve a symbolic purpose for the family, in an Indian context where certificates, photo opportunities, and publicity carry tremendous weight through validation (family validation is an important missing piece in the funding issues noted by [25], [66]). The pressure to get married at this life stage is countered indirectly through scholarships, which provide families the social status and currency, at the same time allow the daughters to study further. Unfortunately there are not enough women-centric scholarships in India, and even if they exist, the awareness is limited to elite universities-making these programs discoverable is key to wider impact on women.

\section{Public engagement of $\mathrm{HCl}$}

The same socio-cultural factors that make CS degrees desirable work against $\mathrm{HCI}$ education and practice in this milieu; HCI falls under design and arts, which are not seen as feeder channels for software jobs (complementing US-based insights [19, 18]). The highlighting of $\mathrm{HCI}$ as a career option within computing could serve to draw more women into the field, enable more software jobs, develop synergies with computer science research and coworkers, and allow academic publications to be viewed as computing contributions, while also providing women more options when negotiating with their families. The breadth of the field allows the pursuit of careers that some women may find preferable to those involving engineering alone. Should there be "Girls Who HCI" programs alongside "Girls Who Code"? At the same time, HCI researchers and practitioners can expand their role as the conscience of the tech sector, by bringing gender issues to light.

\section{Gainful employment in $\mathrm{HCl}$}

Our research points to the importance of job prospects in the pursuit of educational disciplines (indeed, job stability is one of the core factors for pursuing computing). Universities offering HCI should highlight its career possibilities that may satisfy a broader array of women's occupational preferences, while remaining within the technology sector. The field of HCI may require a push to more strongly associate with the discipline of computer science and be less segregated in nontechnical fields like arts, as in the US where HCI is housed primarily in CS and Information Science departments. Gainful $\mathrm{HCI}$ employment is crucial to choosing the specialization (one reason why some of our engineer participants took up HCI degrees in the United States); the HCI community has a critical role to play in industry and academic job creation.

\section{Relevance to other Global South contexts}

And, what about lessons that can be drawn for other countries? One outcome of our interviews that deserves closer scrutiny is the apparent lack of gender-based ability disparities in India. Girls seemed just as confident as boys in STEM subjects. More research is required, but the gender-equal countries could undoubtedly learn from the strengths of India's approach, of early introduction of computing, lack of gender stereotypes in schools, and positive aspirations around the fields of computing. Other gender-unequal countries could learn from the upward mobility associated with computing, financial independence for women, and the creation of a prosperous IT industry. India, Namibia, South Africa, Brazil and Pakistan are some of the few gender-unequal countries to offer HCI-related programs. While India's HCI challenges are many, extending the research to other gender-unequal countries where $\mathrm{HCI}$ is up-and-coming amidst similar aspirational values around the technology sector can help understand gender challenges.

Beyond that, however, our findings offer a few practical recommendations for the gender-equal contexts. Parents cannot be expected to exert hard pressure on their girl children to enter computer science, and even persuasive tactics based on greater financial and marriage prospects seem fraught. As noted by some work in cross-cultural sociology, occupational gender disparities are greater in gender-equal countries for reasons linked to an indulging of essentialist stereotypes [11]. Perhaps the largest lesson of our study for contexts where concern about women's representation in technology is significant is further confirmation that gender disparities in the technology sector are not inevitable. Cultural forces lead to great variation in the representation of women, and can presumably be changed over time with concerted effort.

\section{CONCLUSION}

We presented the gender-related complexities that Indian women face in computing and HCI throughout their life time, drawing from qualitative research with Indian researchers, practitioners, and students. Against a backdrop of entrenched gender discrimination and relatively low literacy rates, India provides a interesting case study of women in computing. Cultural and economic expectations around working in the software industry forged supportive environments for women in the undergraduate and Master's levels (45\% women in undergraduate CS programs); but swiftly devolved into discrimination and eventual exit from Ph.D., academia, and IT jobs (where women constitute $80 \%$ of entry-level jobs). Specifically, societal stigma against highly qualified women, limited female role models for the family, unfriendly work policies, and delayed promotions affect professional progress. HCI suffers from the converse effect-in viewing HCI education as arts-centric, the field was viewed as less desirable to enter the IT force (only an estimated 25-30\% women in HCI programs). Over and above the perception, women were discriminated in the core aspects of HCI research, such as fieldwork, brainstorming, and design critiques.

Future work could extend inquiry to lower-tier colleges, other gender-inequal countries, and include parents and partners of women. We hope that by bringing attention to the societal influence on women's education and careers, we can move towards more equitable computing and $\mathrm{HCI}$ for all.

\section{ACKNOWLEDGEMENTS}

We wish to thank our research participants, Ashwani Sharma, Garen Checkley, Asif Baki, Vaibhavi Desai, Taylor Herr, Maggie Johnson, David Shapiro, Mo Fong, Jason Ravitz, and Chris Stephenson. 


\section{REFERENCES}

1. 2017 (accessed December 30, 2017). The Global Gender Gap Report 2017. Technical Report. World Economic Forum. https://goo.gl/SEoSJt.

2. Emmaneul Amberber. In 2016, $\$ 4$ billion invested in Indian startups $=\mathrm{https}: / / \mathrm{goo} . \mathrm{gl} / 5 \mathrm{k} 7 \mathrm{weK}$, month $=$ December, year $=$ 2016.

3. The World Bank. 2016. Labor force participation rate, female. (2016). https://goo.gl/rFRWkQ.

4. Shaowen Bardzell. 2010. Feminist HCI: taking stock and outlining an agenda for design. In Proceedings of the SIGCHI conference on human factors in computing systems. ACM, $1301-1310$.

5. Shaowen Bardzell, Elizabeth Churchill, Jeffrey Bardzell, Jodi Forlizzi, Rebecca Grinter, and Deborah Tatar. 2011. Feminism and interaction design. In CHI'11 Extended Abstracts on Human Factors in Computing Systems. ACM, 1-4.

6. Greg Baumann. Google cracks Silicon Valley's wall of silence on workforce diversity, confirming that it is largely white and male $=$ https: $/ /$ goo.gl/J2Ff1c, month $=$ May, year $=2014$.

7. Francis Bloch, Vijayendra Rao, and Sonalde Desai. 2004. Wedding celebrations as conspicuous consumption signaling social status in rural India. Journal of Human Resources 39, 3 (2004), 675-695.

8. Stephen J. Ceci, Donna K. Ginther, Shulamit Kahn, and Wendy M. Williams. 2014. Women in Academic Science. Psychological Science in the Public Interest 15, 3 (2014), 75-141. DOI : http://dx. doi .org/10.1177/1529100614541236 PMID: 26172066.

9. Chakreview. "2017 (accessed August 31, 2017)". Top 10 Highest Paying Jobs in India. https: //goo.gl/YHsrgK.

10. Mona Chalabi. "2017 (accessed August 31, 2017)". Internationally, Women Still Spend More Time Doing Chores Housework. https://goo.gl/dqjVCz.

11. Maria Charles and Karen Bradley. 2009. Indulging our gendered selves? Sex segregation by field of study in 44 countries. American journal of sociology 114, 4 (2009), 924-976.

12. Sapna Cheryan, Allison Master, and Andrew N Meltzoff. 2015. Cultural stereotypes as gatekeepers: increasing girlsâĂŹ interest in computer science and engineering by diversifying stereotypes. Frontiers in psychology 6 (2015).

13. J McGrath Cohoon, Zhen Wu, and Jie Chao. 2009. Sexism: toxic to women's persistence in CSE doctoral programs. In ACM SIGCSE Bulletin, Vol. 41. ACM, 158-162.

14. Shelley J Correll. 2004. Constraints into preferences: Gender, status, and emerging career aspirations. American sociological review 69, 1 (2004), 93-113.

15. Ruth Schwartz Cowan. 1983. More work for mother: The ironies of household technology from the open hearth to the microwave. Vol. 5131. Basic Books.

16. Sonali Das, Sonali Jain-Chandra, Kalpana Kochhar, and Naresh Kumar. 2015. Women workers in India: why so few among so many? (2015).

17. Deloitte. Women in IT jobs: it is about education, but also about more than just education $=$ https: //goo.gl/XDEY8n, year $=$ 2016.

18. Susan M Dray, Daniela K Busse, Anke Marei Brock, Anicia N Peters, Shaowen Bardzell, Allison Druin, Margaret M Burnett, Elizabeth F Churchill, Gayna Williams, Karen Holtzblatt, and others. 2014. Perspectives on gender and product design. In CHI'14 Extended Abstracts on Human Factors in Computing Systems. ACM, 53-56.

19. Susan M Dray, Anicia N Peters, Anke M Brock, Andrea Peer, Allison Druin, Shikoh Gitau, Janaki Kumar, and Dianne Murray. 2013. Leveraging the progress of women in the HCI field to address the diversity chasm. In CHI'13 Extended Abstracts on Human Factors in Computing Systems. ACM, 2399-2406.
20. Maya Escueta, Tushar Saxena, and Varun Aggarwal. 2013 (accessed August 20, 2017). Women in Engineering:A comparative study of barriers across Nations. Technical Report. Aspiring Minds India. https://goo.gl/kVLVEh.

21. Henry Etzkowitz, Carol Kemelgor, Michael Neuschatz, and Brian Uzzi. 1992. Athena unbound: Barriers to women in academic science and engineering. Science and Public Policy 19, 3 (1992), 157-179.

22. Susan Kolker Finkel and Steven G Olswang. 1996. Child rearing as a career impediment to women assistant professors. The Review of Higher Education 19, 2 (1996), 123-139.

23. Allan Fisher and Jane Margolis. 2002. Unlocking the clubhouse: the Carnegie Mellon experience. ACM SIGCSE Bulletin 34, 2 (2002), 79-83.

24. Institute for Family Studies (IFS). "2016 (accessed August 23, 2017)". Better-Educated Women Still Prefer Higher-Earning Husbands. https://goo.gl/7KZRyL.

25. Vashti Galpin. 2002. Women in computing around the world. ACM SIGCSE Bulletin 34, 2 (2002), 94-100.

26. Melissa Gregg. "2015 (accessed August 8, 2017)". The Deficiencies of Tech's 'Pipeline' Metaphor. https://goo.gl/SPKyBu.

27. Namrata Gupta. 2012. Women undergraduates in engineering education in India: A study of growing participation. Gender, Technology and Development 16, 2 (2012), 153-176.

28. Namrata Gupta. 2015. Rethinking the relationship between gender and technology: a study of the Indian example. Work, employment and society 29, 4 (2015), 661-672.

29. Namrata Gupta and Arun K Sharma. 2003. Gender inequality in the work environment at institutes of higher learning in science and technology in India. Work, employment and society 17, 4 (2003), 597-616.

30. Jo Handelsman, Nancy Cantor, Molly Carnes, Denice Denton, Eve Fine, Barbara Grosz, Virginia Hinshaw, Cora Marrett, Sue Rosser, Donna Shalala, and others. 2005. More women in science. Science 309, 5738 (2005), 1190-1191.

31. Steve Henn. When Women Stopped Coding =https: $/ /$ goo.gl/XqkY72, month $=$ October, year $=2014$.

32. Catherine Hill, Christianne Corbett, and Andresse St Rose. 2010. Why so few? Women in science, technology, engineering, and mathematics. ERIC.

33. Hai Hong, Jennifer Wang, Jason Ravitz, and Mo-Yun Lei Fong. 2015. Gender Differences in High School Students' Decisions to Study Computer Science and Related Fields. In SIGCSE. 689.

34. IBEF. "2017 (accessed August 23, 2017)". IT \& ITeS Industry in India. https://goo.gl/koCxdN.

35. Kori Inkpen. 1997. Three important research agendas for educational multimedia: Learning, children and gender. In AACE World Conference on Educational Multimedia and Hypermedia, Vol. 97. 521-526.

36. Amanda Kimball. 2011. UC Davis study of California women business leaders: A census of women directors and highest-paid executives. Graduate School of Management, University of California, Davis.

37. Stephan Klasen and Janneke Pieters. 2015. What explains the stagnation of female labor force participation in urban India? The World Bank Economic Review 29, 3 (2015), 449-478.

38. Nalini P Kotamraju. 2011. Playing stupid, caring for users, and putting on a good show: Feminist acts in usability study work. Interacting with Computers 23, 5 (2011), 439-446.

39. Anne Krook. "2017 (accessed August 23, 2017)". Tech and the Gender Pay Gap. https: //goo.gl/HLjBns. 
40. Ann Light, Ilda Ladeira, Jahmeilah Roberson, N Bidwell, Nimmi Rangaswamy, Nithya Sambasivan, and Shikoh Gitau. 2010. Gender matters: Female perspectives in ICT4D research. (2010).

41. Farhad Manjoo. 2014. Exposing Hidden Bias at Google - The New York Times. https: //goo.gl/EmaqNq. (September 2014). (Accessed on 09/02/2017).

42. Jane Margolis, Allan Fisher, and Faye Miller. 1999. Caring about connections: Gender and computing. IEEE technology and society magazine 18, 4 (1999), 13-20.

43. Jane Margolis, Allan Fisher, and Faye Miller. 2000. The anatomy of interest: Women in undergraduate computer science. Women's Studies Quarterly 28, 1/2 (2000), 104-127.

44. J Margolis, A Fisher, and F Miller. 2002. Caring about connections: Gender and computing. Pittsburgh. (2002).

45. Catherine Mavriplis, Rachelle Heller, Cheryl Beil, Kim Dam, Natalya Yassinskaya, Megan Shaw, and Charlene Sorensen. 2010. Mind the gap: Women in STEM career breaks. Journal of technology management \& innovation 5, 1 (2010), 140-151.

46. Kristen Monroe, Saba Ozyurt, Ted Wrigley, and Amy Alexander. 2008. Gender equality in academia: Bad news from the trenches, and some possible solutions. Perspectives on politics 6, 2 (2008), 215-233.

47. Corinne A Moss-Racusin, John F Dovidio, Victoria L Brescoll, Mark J Graham, and Jo Handelsman. 2012. Science facultyâĂŹs subtle gender biases favor male students. Proceedings of the National Academy of Sciences 109, 41 (2012), 16474-16479.

48. C.C Mukhopadhyay. 1996. The cultural context of gendered science: a theoretical model derived from studies in India. Gates 3, 1 (1996).

49. Brian A Nosek, Frederick L Smyth, Natarajan Sriram, Nicole M Lindner, Thierry Devos, Alfonso Ayala, Yoav Bar-Anan, Robin Bergh, Huajian Cai, Karen Gonsalkorale, and others. 2009. National differences in gender-science stereotypes predict national sex differences in science and math achievement. Proceedings of the National Academy of Sciences 106, 26 (2009), 10593-10597.

50. Central Institute of Educational Technology. 2013. Information and Communication Technology for the School System: Curricula for ICT in Education. Technical Report. National Council of Educational Research and Training.

51. Ministry of Human Resource Development. 2015-16. All India Survey on Higher Education. Technical Report. Government of India,Ministry of Human Resource Development, Department of Higher Education, Statistics Division.

52. PTI. JEE Main: Number of students appearing have declined, says Govt=https://goo.gl/LufVED, month $=$ April, year $=$ 2017.

53. Parvati Raghuram, Clem Herman, Esther Ruiz-Ben, and Gunjan Sondhi. 2017. WOMEN AND IT SCORECARD-INDIA. (2017).
54. Thillai Rajan. Trends in StartUp Ecosystem and Financing =https: $/ /$ goo.gl/GJE9eb, month $=$ February, year $=2017$.

55. Vaidyeswaran Rajaraman. 2015. History of Computing in India: 1955-2010. IEEE Annals of the History of Computing 37, 1 (2015), 24-35.

56. Sheryl Sandberg. Lean In. =https://leanin.org/book/, month $=$ June, year $=2010$. (????).

57. Christine Satchell. 2010. Women are people too: The problem of designing for gender. (2010).

58. Ari Schlesinger, W Keith Edwards, and Rebecca E Grinter. 2017. Intersectional HCI: Engaging Identity through Gender, Race, and Class. In Proceedings of the 2017 CHI Conference on Human Factors in Computing Systems. ACM, 5412-5427.

59. Scroll. "2017 (accessed August 23, 2017)". Indians are working too much $\hat{a} \breve{A} S$ and it's making them sick and tired. https://goo.gl/ldjNDE.

60. Steven J Spencer, Claude M Steele, and Diane M Quinn. 1999. Stereotype threat and women's math performance. Journal of experimental social psychology 35, 1 (1999), 4-28.

61. Statista. 2017. Size of the IT Industry in India as a share of India's gross domestic product from 2008 to 2016. (2017). data retrieved from, https://goo.gl/zBYNiC.

62. Andrea H Tapia and Lynette Kvasny. 2004. Recruitment is never enough: retention of women and minorities in the IT workplace. In Proceedings of the 2004 SIGMIS conference on Computer personnel research: Careers, culture, and ethics in a networked environment. ACM, 84-91.

63. David R Thomas. 2006. A general inductive approach for analyzing qualitative evaluation data. American journal of evaluation 27, 2 (2006), 237-246.

64. Maria Thomas. 2016. When it comes to feminism, neither Bollywood nor India Inc.'s advertisements have got it right.

65. Roli Varma. 2010. Forms of Social Asymmetry and Cultural Bias: Of Gender and Science in India and the World. Journal of Women and Minorities in Science and Engineering 16 (2010). Issue 3.

66. Sujata Venkatesh. 2015. Forms of Social Asymmetry and Cultural Bias: Of Gender and Science in India and the World. Transcience (2015) 6, 1 (2015).

67. Brian Welle and Madeline E Heilman. 2007. Formal and informal discrimination against women at work. Research in social issues in management: Managing social and ethical issues in organizations (2007), 229-252.

68. Julie A. Winkler. 2000. Faculty Reappointment, Tenure, and Promotion: Barriers for Women. The Professional Geographer 52, 4 (2000), 737-750. DOI : http: //dx. doi .org/10.1111/0033-0124.00262

69. Nicholas H Wolfinger, Mary Ann Mason, and Marc Goulden. 2008. Problems in the pipeline: Gender, marriage, and fertility in the ivory tower. The Journal of Higher Education 79, 4 (2008), 388-405. 